\title{
Perspectivas da participação do público através de ONGs para a gestão ambiental na América Latina
}

\author{
Gabriel Eduardo Schütz* \\ Carlos Machado de Freitas** \\ Sandra Hacon***
}

\section{Resumo}

Este artigo analisa algumas perspectivas e limitações das organizações não-governamentais (ONGs) como instância de participação popular para a gestão ambiental local e regional na América Latina. Em primeiro lugar, é analisado 0 fundamento ético do trabalho voluntário independente nas democracias regionais e sua relação com a formulação de políticas públicas - principalmente nas áreas de saúde e meio ambiente - no processo de globalização da economia mundial.

Este estudo também apresentada uma análise qualitativa de dados demográficos, socioeconômicos e ambientais que correlacionam a referência espacial das ONGs com as paradoxais realidades sociopolíticas e socioeconômicas do continente americano. Tenta-se mostrar que setores governamentais e do empresariado vêm estimulando a substituição da solidariedade compulsória das políticas sociais compensatórias pela filantropia e o trabalho voluntário, e que essa tendência é coerente com a reestruturação do capitalismo mundial. Os dados demonstram que, em geral, as ONGs não aparecem e prosperam na pobreza, mas nas áreas de concentração de poder político-econômico associado ao desenvolvimento humano. É discutida a diferença conceitual entre sociedade civil e terceiro setor, comumente identificados como sinônimos.

Finalmente, são apresentadas conclusões que podem servir de estímulo para que gestores e o público em geral reflitam sobre o projeto político e econômico que está por trás do incentivo ao trabalho voluntário em áreas de responsabilidade do Estado, como são as áreas de saúde pública e gestão ambiental.

Palavras-chave: organizações não- governamentais; políticas públicas; gestão ambiental; desenvolvimento sustentável.

\section{Abstract}

This article analyzes some perspectives and limitations of the non-governmental organizations (NGOs) as formal mechanism for citizen's participation in local and regional environment management in Latin America. First, the ethical basis of the independent voluntary work in underdeveloped countries democracies are analyzed in relation with the policy-maker decision process in the framework of economical globalization, mainly in public health and environment policies. Secondly, it is displayed a qualitative analysis of demographic, social, economical and environmental data that correlate the spatial references of the NGOs with the paradoxical social reality in Latin American.

This paper tries to show that some governmental and corporate sectors stimulates the substitution of solidarity for philanthropic in the social politics and also this trend is coherent with the global reorganization of the capitalism. Qualitative analysis shows that mostly of the NGOs do not appear and prosper in poverty areas, but in the rich areas with high political and economical power concentration and correlate to Human Development Index. In this context, it is necessary to make a conceptual differentiation between civil society and the third sector, usually wrongly identified as synonymous.

Finally, conclusions seek to lead on a policy-makers moral reflection about a political model that encourages no-political voluntary work instead of State responsibility in social areas, especially in public health and environmental management.

Key words: non-governmental organizations; public policies; environmental management; sustainable development.

\section{* Gabriel Eduardo Schütz}

Doutorando da Escola Nacional de Saúde Pública - ENSP da Fundação Oswaldo Cruz - FIOCRUZ. E-mail: gabriel@ ead.fiocruz.br. Endereço: Av. Leopoldo Bulhões 1480

- Manguinhos - CEP: 21040-210, Rio de Janeiro - RJ.

* Carlos Machado de Freitas

Pesquisador do Centro de Estudos de Saúde do Trabalhador e Ecologia Humana

Escola Nacional de Saúde Pública - ENSP da Fundação Oswaldo Cruz - FIOCRUZ. E-mail: carlosmf@ ensp.fiocruz.br. Endereço: Av. Leopoldo Bulhões 1480 -

Manguinhos - CEP: 21040-210, Rio de Janeiro - RJ.

*

Pesquisadora do Departamento de Endemias Samuel Pessoa da Escola Nacional de Saúde Pública - ENSP da Fundação Oswaldo Cruz - FIOCRUZ. E-mail:

shacon@ ensp.fiocruz.br. Endereço: Av. Leopoldo Bulhões 1480 - Manguinhos - CEP: 21040-210, Rio de Janeiro - RJ.

Artigo recebido em maio de 2005 e aceito para publicação em julho de 2005. 


\section{Introdução}

Uma gestão ambiental comprometida com o desenvolvimento sustentável, com a justiça ambiental e com a democracia deve promover e facilitar o diálogo e a negociação com a sociedade civil. Porém, que sociedade civil é essa? É possível representá-la?

A participação da sociedade civil no planejamento e na gestão ambiental é um assunto que ganha cada vez mais destaque na agenda de agências multilaterais como o Banco Mundial e o Fundo Monetário Internacional (WB, 2004b). Com foco na realidade socioambiental da América Latina e Caribe, este artigo pretende discutir algumas das limitações do modelo de participação da sociedade civil que vem sendo promovido a partir de setores vinculados ao poder político e econômico mundial, segundo o qual, o terceiro setor, materializado de forma ambígua nas organizações não-governamentais (ONGs), representaria a sociedade civil. O objetivo é também demonstrar, através de uma análise ética e política, que identificar o conceito de "sociedade civil" com o de terceiro setor e reduzi-lo às ONGs é parte do mesmo projeto econômico neoliberal global causador de grande parte dos mais sérios problemas ambientais.

Ao promover o terceiro setor como instância de participação e de gestão socioambiental, o objetivo das agências internacionais de financiamento não seria apenas reduzir a influência do Estado nas decisões, mas também, responsabilizar a sociedade civil pelas consequiências do modelo econômico vigente, através do convite ao público para "participar e fazer sua parte". Como afirma Eduardo Galeano, a estratégia neoliberal é passar a mensagem de que todos nós somos responsáveis pela ruína do planeta, porém "se todos nós somos responsáveis, ninguém é responsável" (GALEANO, 2004, p.9)

No entanto, para os gestores ambientais que enfrentam o desafio de dialogar e negociar com comunidades locais e organizações que de um modo ou de outro representam o público, a identificação dos legítimos interlocutores da sociedade civil é um problema cotidiano de difícil solução. Isso ocorre, especialmente, pelo fato de que os problemas ambientais, seguindo de perto as atividades econômicas e financeiras, vêm ganhando dimensões globais e envolvendo uma enorme e complexa rede de interesses e atores sociais, muitas vezes antagônicos.

Pode ser constatado que, nas últimas décadas, os efeitos da degradação e da exploração do meio ambiente deixaram de ser percebidos apenas no âmbito local, circunscrito e visível, como a questão dos rios poluídos ou das matas desflorestadas. Paulatinamente, o impacto ambiental começou a envolver regiões cada vez mais amplas até alcançar uma dimensão global de comprometimento do planeta, como no caso da mudança climática (McMICHAEL, 1993). Essa dimensão global é um desafio à maneira como está organizada a vida social e institucional, pois as decisões passam a envolver valores e interesses de comunidades estranhas entre si, pertencentes a regiões tão afastadas quanto desconhecidas. Por sua parte, os governos e as instituições tornamse cada vez mais conscientes da impossibilidade de separar as questões relativas ao desenvolvimento econômico das questões ambientais, uma vez que as atividades econômicas dependem dramaticamente da manutenção dos ecossistemas. Essas preocupações levaram a Assembléia Geral da ONU a criar, em 1983, a Comissão das Nações Unidas sobre Meio Ambiente e Desenvolvimento (CGG, 1996). Essa comissão percebeu que a tendência de desenvolvimento vigente resultava em aumento da pobreza e danos cada vez maiores ao meio ambiente. Isso levou à necessidade de se discutir um modelo de desenvolvimento econômico capaz de manter o progresso humano não apenas em alguns lugares e por alguns anos, mas em todo o planeta e até um futuro longínquo. O conceito de "desenvolvimento sustentável", portanto, era lançado na agenda do debate ambiental.

Durante a Conferencia das Nações Unidas sobre Meio Ambiente e Desenvolvimento - realizada em Rio de Janeiro em 1992 - foi acordado um programa para o desenvolvimento sustentável, a Agenda 21. No documento constava uma série de compromissos a serem assumidos pelos países signatários, entre os quais, o de incorporar em suas políticas públicas princípios de sustentabilidade (OPS, 1993). Contudo, os resultados 
apresentados na Conferencia de Johanesburgo em 2002, a "Rio+10", demonstraram que poucos dos compromissos assumidos na Agenda 21 foram postos em prática (ONU, 2004a).

A possibilidade de alcançar um verdadeiro desenvolvimento sustentável é um enorme desafio político internacional, uma vez que as diferentes regiões do planeta não participam de maneira equiitativa nem da produção nem da distribuição da riqueza gerada a partir dos recursos materiais e energéticos extraídos dos ecossistemas. Tampouco é equiitativa a distribuição dos riscos e da vulnerabilidade aos efeitos do impacto ambiental. No entanto, a Comissão da ONU sobre Meio Ambiente e Desenvolvimento afirma que o desenvolvimento sustentável - como um processo de mudança institucional - só poderá se concretizar pela equiidade e por abordagens abrangentes que assimilem a participação popular nas decisões. Deve ser levado em conta que ambos os requisitos estão intimamente relacionados, pois equiidade pressupõem sistemas políticos que assegurem a participação efetiva da sociedade nas decisões; isto é, são necessários processos decisórios mais democráticos no âmbito internacional (CGG, 1996).

Hoje, duas décadas depois de iniciado o debate sobre desenvolvimento sustentável - apesar do enorme quantidade de ONGs, de todos os tipos e tendências, surgidas nesses anos - as instituições em todos os níveis (local, nacional e internacional) continuam a enfrentar os desafios da sustentabilidade, de maneira independente e fragmentada, com atribuições relativamente limitadas e processos de decisão fechados. Principalmente, o traçado da política econômica através de planos de investimentos e de desenvolvimento continua desvinculado da formulação de políticas públicas para a proteção do meio ambiente e da saúde humana. Política ambiental e de saúde pública também estão desvinculadas uma da outra, tanto na avaliação dos problemas quanto na implementação das intervenções (OPS, 1993).

É evidente a necessidade política de que sejam criados espaços intersetoriais onde os diferentes atores sociais possam participar do processo decisório e da formulação de políticas públicas. Segundo a Comissão das Nações Unidas sobre Governança Global,

"hoje, o poder coletivo das pessoas para manejar o futuro é maior do que nunca, e a necessidade de exercê-lo é mais imperiosa. O principal desafio dessa geração é mobilizar tal poder para tornar a vida mais democrática, mais segura e mais sustentável no século XXI" (CGG, 1996, p.1).

Agora, é a vez de ser lançado o conceito de "governança" no debate ambiental. Entende-se por governança o "processo contínuo pelo qual é possível acomodar interesses conflitantes ou diferentes, e realizar ações cooperativas" (ibidem, p.2). Em outras palavras, governança é a totalidade das diversas maneiras pelas quais os indivíduos e as instituições, públicas e privadas, administram seus problemas comuns através de um amplo, dinâmico, complexo e interativo processo decisório.

É obvio que não há uma fórmula preestabelecida para exercer a governança- nem local, nem global -, uma vez que o processo decisório participativo é um assunto tão novo quanto complexo, que requer mecanismos de interatividade das práticas sociais. Porém, há um perfil para pensar a participação dos stakeholders no gerenciamento dos conflitos de interesses que conta com maior aprovação no âmbito do poder econômico real; isto é, nos governos e nas grandes empresas privadas: o chamado terceiro setor, em princípio, definido como aquilo que não é nem governo, nem capital.

Tão heterogêneas quanto fragmentadas e antagônicas, as atividades do terceiro setor aparecem no imaginário popular identificadas e reduzidas às ações das organizações não-governamentais (ONGs); ou seja, de associações civis autoconvocadas, legitimadas pelo direito civil da livre associação e caracterizadas pelo trabalho voluntário convocado através do discurso da "cidadania". Obviamente, o conceito de terceiro setor é uma abstração tanto quanto o conceito de Estado ou de sociedade civil; portanto, quando se escolhe e legitima um "representante" para esses conceitos, há, de fato, um exercício de poder para que seja imposto um modelo hegemônico. 


\section{0 discurso ético do terceiro setor}

Hoje em dia, existe um discurso hegemônico sobre a participação dos cidadãos nas questões públicas. É o discurso sobre terceiro setor, capital social, trabalho voluntário e cidadania, dentre outros conceitos ambíguos. Esse discurso forma parte da produção simbólica que acompanha a reestruturação do capitalismo, com a abertura da China ao mercado mundial e o colapso do bloco dos países socialistas no Leste europeu, depois da queda do Muro de Berlim em 1989. É que a reestruturação da economia capitalista sob o modelo neoliberal globalizado não poderia ter sido imposta sem uma produção simbólica que, na forma de discursos de conteúdo ético, conseguisse sujeitar, mascarar ou disfarçar conflitos e tensões capazes de ameaçar o seu sucesso. Segundo Álvaro de Vita, as razões para o êxito da ideologia neoliberal não devem ser procuradas unicamente no seu pragmatismo econômico, mas também na hábil combinação de um conjunto de críticas morais aos desgastados padrões de intervenção estatal que tomaram forma, principalmente no pós-II Guerra Mundial, sob o argumento da justiça (VITA, 2000).

Aos poucos, a demanda popular por justiça social foi sendo substituída pela cidadania em um contexto de liberalização total da economia e reinado absoluto da racionalidade das leis do mercado sobre as velhas e corrompidas fórmulas do intervencionismo estatal. Porém, essa substituição de termos e de discursos éticos não tem unicamente conotação semântica. Tradicionalmente, quando o que está em questão é a justiça social, enfoca-se os direitos sociais (trabalho, saúde, educação e assistência social). Entretanto, quando o que está em questão é a cidadania, o foco se volta para os direitos civis (liberdade, propriedade e segurança, dentre outros).

Direitos sociais e direitos civis têm origem e natureza diferentes. Os direitos civis têm total universalidade em seu gozo, pois se não forem gerais perdem seu sentido. Por sua vez, os direitos sociais não compartilham essa "indistinção", visto que as diferenças entre as pessoas - especialmente, a vulnerabilidade social - devem ser levadas em conta na hora de implementar tais direitos (DOMINGUES, 2001).

Norberto Bobbio afirma que a perspectiva histórica dos direitos está vinculada ao surgimento da concepção individualista moderna. Segundo Bobbio, os direitos não nascem todos de uma vez, e sim paulatina e historicamente. Para ele os direitos civis surgem da luta dos Parlamento contra os soberanos absolutos; os direitos políticos e sociais, dos movimentos populares (BOBBIO, 1992). Todavia, a diferença essencial entre direitos sociais e direitos civis é que os primeiros, para serem implementados - em vez de demandarem a limitação do poder do Estado, como fazem os civis - exigem a intervenção ativa do Estado na vida social (BOBBIO, 1992). Podemos afirmar que os direitos sociais, instrumentalizados pelo Estado, surgem, paradoxalmente, como consequiência da ampliação da cidadania através do direito político do voto. Quando os proprietários eram os únicos que tinham direito de voto, era natural que pedissem ao poder público o exercício de uma função primária: a proteção da propriedade. Nascia, então, a doutrina do Estado limitado, do Estado mínimo; configurando-se o Estado como associação dos proprietários para a defesa daquele direito natural supremo que era, para John Locke, o direito à propriedade (LOCKE, 2001). A partir do momento em que o voto foi estendido aos que não tinham propriedade, aos que tinham somente a força de trabalho, começou a ser exigido do Estado a proteção contra o desemprego, seguros sociais contra a doença e contra a velhice, providências em favor da maternidade, habitação popular etc. Com isso, o Estado, nas democracias capitalistas da Europa ocidental se transformaria no Estado de Bem-Estar (Welfare State), constituindo, assim, as "democracias sociais". A partir desse momento, contudo, foi preciso arcar com um ônus desconhecido pelo Estado das oligarquias burguesas e das "democracias liberais" que lhe precederam (BOBBIO, 1986).

É preciso atentar para o fato de que o discurso ético da democracia social se diferencia do correspondente liberal na instrumentalização da liberdade como valor moral supremo do cidadão. Para o primeiro, o instrumento para alcançar a liberdade do indivíduo é a justiça social - regulada pelo Estado através da regulamentação dos direitos sociais -; no segundo caso, esse instrumento só pode ser a propriedade, regulada pelo mercado livre e pelo respeito aos direitos civis. 
O Welfare State - surgido no pós-II Guerra Mundial como um pacto harmonizador para manter o capitalismo europeu (SANTOS, 1987) - entende que a liberdade somente é alcançada quando todo cidadão possui as condições materiais de bem-estar (trabalho digno, saúde, educação) suficientes para alcançar a autonomia que lhe permita autonomamente exercer escolhas verdadeiras. Isso obriga o Estado a regulamentar os direitos sociais, que somente através de políticas públicas podem ser planejados e gerenciados de maneira eqüitativa, integral e simultânea para todos os cidadãos. Da perspectiva moral do Welfare State, as condições materiais (como o direito à saúde) que facilitam a autonomia do cidadão mais vulnerável são consideradas tão importantes eticamente, a ponto de fundamentarem a imposição de um dever (o de pagar impostos) a outro cidadão mais privilegiado (VITA, 2000).

Já o neoliberalismo - surgido na década de 1980 com os governos Thatcher (Reino Unido) e Reagan (EUA) e consolidado com o fim da Guerra Fria a partir de 1989 - considera que a liberdade individual somente pode ser instrumentalizada se cada cidadão tiver garantidos seus direitos civis, principalmente, $\mathrm{o}$ direito à propriedade $\mathrm{e}$ ao cumprimento dos contratos. Desse ponto de vista, a única instância reguladora possível é o mercado livre. O Estado deve limitar-se a institucionalizar deveres e constrições contra situações e atitudes que possam ameaçar a vigência dos direitos civis (VITA, 2000).

Na construção do seu discurso ético, o neoliberalismo recupera dois princípios do liberalismo tradicional: o do Estado mínimo, no envolvimento nas questões sociais, e o do Estado neutro, em respeito às relações entre seus cidadãos; isto, por considerar todos autonomamente iguais na hora de assinar o contrato social. Segundo esse modelo, a forma de tomar conta da questão social esquiva-se da esfera do direito, ficando aquém dela. Em vez de um espaço público politizado, a política social do liberalismo reivindica um espaço público meramente ético. Em vez de obrigações do Estado (que deve ser mínimo), o liberalismo põe em cena a obrigação moral de ser caridoso, uma vez que os integrantes das "classes inferiores"(especialmente, as crianças) não têm capacidade de conduzir suas vidas, cabendo à beneficência fazê-lo (DOMINGUES, 2001).

Para os pensadores da ética (neo)liberal (NOZICK, 1974; ENGELHARDT, 1998), contribuir para minorar o sofrimento de pessoas que passam por dificuldades pode ser meritório (e desejável), em especial, para quem tem condições estruturais e materiais para se envolver com o trabalho voluntário. Mas o sofrimento social dos cidadãos vulneráveis não autoriza moralmente o Estado a tomar compulsoriamente recursos - por mínimos que sejam - dos cidadãos privilegiados para distribuições sociais compensatórias. Se isso acontecesse, já não seria um Estado neutro, mas um Estado que arbitrariamente toma partido dos cidadãos mais pobres em prejuízo dos mais ricos (VITA, 2000). Para o neoliberalismo, esse "populismo", além de indesejável para a "saúde" dos mercados, é moralmente indefensível.

É através desse discurso ético que, no processo de reestruturação global do capitalismo, depois da Guerra Fria, o terceiro setor e o trabalho voluntário passam a ser chamados de "participação da sociedade civil" e se convertem na forma eticamente mais "adequada" para levar "cidadania" aos menos privilegiados. Na verdade, trata-se de substituir a solidariedade compulsória das políticas sociais compensatórias (financiadas através da "solidariedade compulsória") pelo trabalho voluntário (financiado pela filantropia) dos grupos sociais privilegiados.

\section{Da Agenda 21 à sociedade civil e a responsabilidade social}

Mas, quem está realmente em condições práticas de participar de projetos voluntários? Para Eduardo Galeano a pressão exercida sobre as massas populares para que aumentem seu consumo, consome, além dos recursos naturais e culturais do planeta, o tempo das pessoas. Paradoxalmente - como consequiência das políticas liberais de flexibilização e de estímulo ao consumo - as pessoas estão com o tempo totalmente ocupado pela necessidade da dupla (quando não múltipla) jornada de trabalho ou presos nos engarrafamentos para voltar para casa. Afinal, ironiza o autor, as pessoas são obrigadas trabalhar mais horas para pagar as parcelas do carro no qual despendem seu tempo nos engarrafamentos (GALEANO, 1994). A ironia do escritor uruguaio nos leva a 
perguntar: que tipo de participação voluntária é possível em países como os latino-americanos, cuja economia capitalista está estruturada na pobreza e na exclusão de um amplo setor da população e, portanto, o status de cidadão é um privilégio de poucos? Até que ponto é sensato nessa região, dispensar o papel das políticas públicas para substituí-las pelo voluntariado? "Caridade" é a mesma coisa que "solidariedade"?

Michael Walzer, no seu livro As esferas da Justiça critica a institucionalização da caridade, pois, segundo o autor, por esse caminho gera-se dependência, condescendência, passividade e submissão por um lado, e arrogância, pelo outro. Para Walzer, a solidariedade, que fundamenta os sistemas de previdência comunitária (destinados a garantir eqüitativamente bem-estar mútuo) não deve ser confundida com a caridade da tradição judaico-cristã de assistir aos pobres (aproveitada explicitamente pelos neoliberais). De fato, para Walzer a caridade seria um exemplo particularmente doloroso do poder do dinheiro em contextos de privação: "todo nosso esforço moral está dirigido à supressão do paternalismo inconsciente e prejudicial do rico que dá esmolas. A caridade pode ser também uma maneira de comprar influências ou estimação" (WALZER, 2001, p.102).

$\mathrm{O}$ fato de que apenas os setores privilegiados da sociedade estejam humanamente estruturados e em condições materiais de se engajar em trabalhos voluntários é um dos argumentos possíveis para explicar porque as ONGs não aparecem e prosperam nas áreas de pobreza e exclusão, mas nas áreas de concentração de poder políticoeconômico. A figura 1 mostra a distribuição geográfica das representações das ONGs no continente americano em termos de densidade. Deve ser observado o padrão particular dessa distribuição geográfica em coincidência com a localização do poder real; isto é, as grandes capitais e as grandes cidades industriais da região. Cabe destacar que o mapa não mostra o local em que as ONGs desenvolvem suas atividades, mas suas sedes, e que somente contabiliza as organizações que ganharam o status de "ONG" definido pela União das Associações Internacionais (UAI), em função do cumprimento de sete requisitos: missão, número de associadosestrutura, sedes, financiamento e relação com as outras associações e atividades (UAI, 2004). Não foi possível obter dados geograficamente referenciados sobre as organizações da sociedade civil não cadastradas pela UAI. 
Figura 1 - Densidade do número de representações das ONGs na América

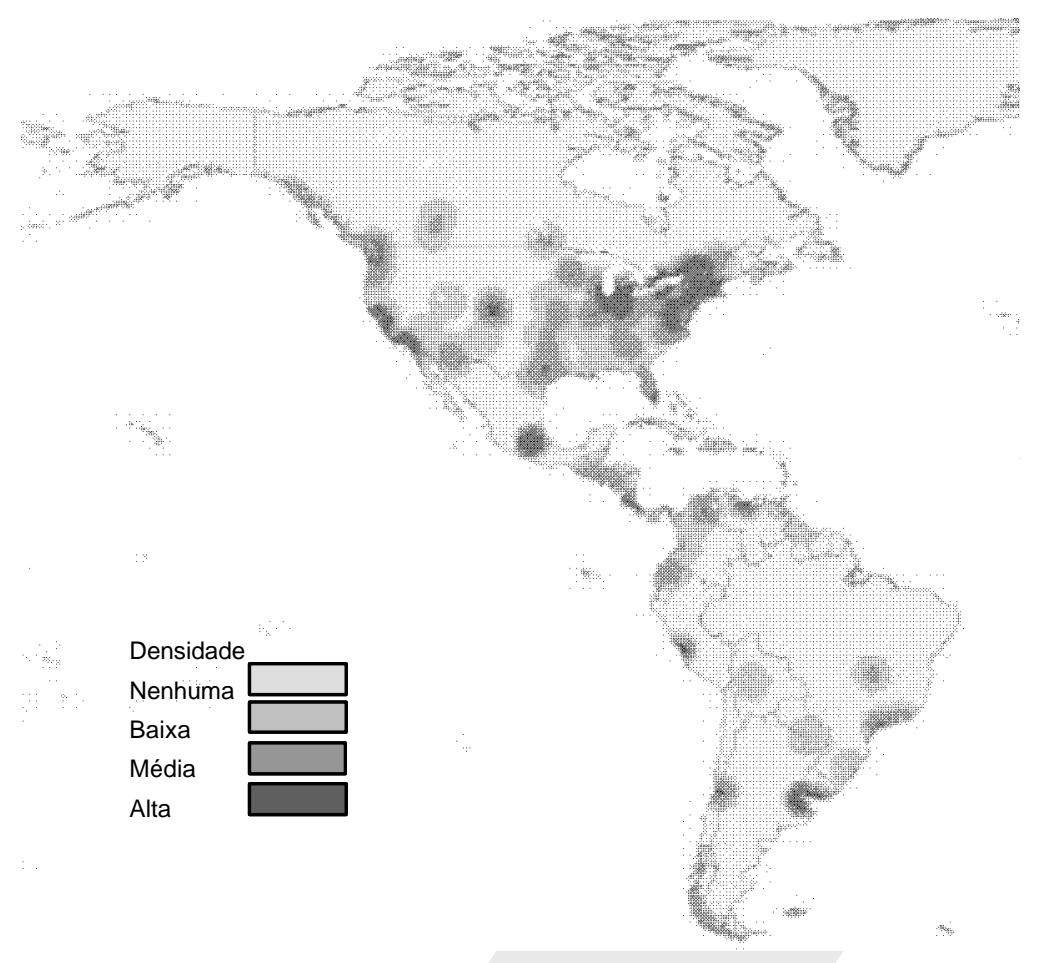

Fonte: GCS (2004).

A discussão das práticas de desenvolvimento sustentável - com seus aspectos político, social, cultural e ambiental - também diz respeito à redefinição das regras de jogo do poder econômico para poder transformar o atual cenário de poluição e desperdício de recursos em outro de conservação; e uma situação de privilégio e protecionismo em outra de oportunidades justas e eqüitativas para todos. É possível dizer que onde há mais poder político e econômico, há mais possibilidade de conflitos de interesses e, portanto, mais motivos e oportunidades para que as pessoas se associem para defender seus direitos ameaçados ou violados, especialmente, direitos civis como segurança e direitos do consumidor. Na verdade, esse é o perfil tradicional da ação das ONGs: uma missão civil que não corresponde à vocação social do terceiro setor para substituir o Estado na questão social. Entretanto, os dados disponíveis não permitem discriminar facilmente as ONGs cuja missão tem vocação civil daquelas ONGs do serviço social, comumente identificadas com o terceiro setor.

Finalmente, outro argumento para explicar o padrão de distribuição geográfica das ONGs é o fato de que o discurso ético do voluntariado neoliberal também foi capitalizado pelas grandes empresas privadas. Essas empresas começaram a incentivar, através de novas políticas de recursos humanos, atividades filantrópicas e de trabalho voluntário (especialmente, nas comunidades pobres próximas a suas sedes) no contexto das chamadas "strong commitments" ou da "responsabilidade social".

Segundo Eduardo Szazi, "responsabilidade social" é um conceito cuja origem está no entendimento da distinção entre "empresa" e "negócio". Um negócio, explica o autor, guia-se basicamente por uma visão de curto prazo e por um interesse centrado no investidor (shareholder), que busca o lucro a qualquer custo. Já a empresa tem uma visão de longo prazo e busca estabelecer relações com os mais diversos grupos de interesse (stakeholders), que incluem fornecedores, empregados, clientes, comunidade e governo, dentre outros (SZAZI, 2000). 
A respeito da gestão ambiental, as grandes empresas privadas mostraram-se eficientes em incorporar ao seu discurso institucional o conceito de "desenvolvimento sustentável" como um importante strong commitment (SCHMIDHEINY, 1992; BRUGGER e LIZANO, 2000).

Na década de 1990, a Organização Internacional para a Normatização (ISO) criou um sistema de normas de gestão ambiental, a série ISO 14000 (VALLE, 2002), que em cada país é controlada pelos respectivos institutos de medidas. A solicitação da certificação ISO 14000 por uma empresa é voluntária, mas, uma vez certificada, a empresa é obrigada a implementar um sistema de gestão e de avaliação ambiental da sua produção (ISO, 2004). As empresas privadas, no entanto, não são obrigadas a dar publicidade a informações que possam comprometêla.

O quadro 1 mostra, para as diferentes regiões do continente americano, o número de ONGs reconhecidas pela UAI, o número de empresas com certificação ISO 14000, além dos indicadores demográficos (população total) e econômicos (PIB e investimentos estrangeiros diretos). Deve ser observada a forte associação entre o maior número de ONGs com sede nas regiões mais desenvolvidas e o número de empresas comprometidas com o cumprimento das normas ISO 14000. Por que essa coincidência? Pelo fato de que as ONGs são mais necessárias quanto mais desenvolvida ambiental e economicamente é uma região e suas instituições, ou porque o maior desenvolvimento econômico faz com que mais pessoas estejam em condições estruturais e se sintam estimuladas a participar das ONGs?

Para dar mais elementos para a análise, o quadro 2 mostra a relação entre esses mesmos indicadores nos diferentes países do continente, agrupados em três conjuntos conforme o número total de ONGs reconhecidas pela UAI, sediadas em seus territórios.

Os dados se referem ao ano de 2002. O número de empresas com certificação ISO 14000 é da Organização Internacional para a Normatização (ISO, 2004). Os dados sobre população total vêm da base de dados da ONU (2004b). O PIB (per capita e total) e os valores dos investimentos estrangeiros diretos foram obtidos na base de dados do Banco Mundial (WB, 2004a). Para calcular o número total de ONGs, foi considerado o status de "ONG" definido pela União das Associações Internacionais (UAI, 2004) e o número total de habitantes do país da base de dados da ONU (2004b).

Ao relacionar qualitativamente o número de ONGs com os indicadores vinculados ao desenvolvimento econômico (em especial, o PIB total e o volume dos investimentos estrangeiros diretos) junto com a referência geográfica das representações de ONGs no continente americano, é confirmada a hipótese de que as atividades dessas organizações não-governamentais não surge nem prospera na pobreza, mas nas áreas onde se concentra o poder político e econômico.

Tal fato se explicaria por uma complexa combinação de argumentos já resumidos anteriormente:

- concentração de pessoas com estrutura humana, disponibilidade material e de tempo para participar voluntariamente de projetos sociais;

- maior probabilidade de conflitos de interesses; e

- incentivo das grandes empresas favorecendo o terceiro setor como parte de sua política de responsabilidade social, dentro de um projeto político neoliberal que visa reduzir a intervenção do Estado, inclusive na questão social.

Essa análise contraria o senso comum, segundo o qual o terceiro setor viria preencher o espaço deixado pelo Estado, uma vez que prospera nas regiões onde o Estado (e/ou o mercado) é mais presente. Ademais, nas áreas onde o Estado é ausente, o terceiro setor também o é. No máximo, poderíamos afirmar que deliberadamente os governos estariam cedendo espaço ao terceiro setor. 
Quadro 1: Relação entre indicadores demográficos, econômicos e de desenvolvimento sustentável por região para o continente americano.

\begin{tabular}{l|r|r|r|r|r}
\hline REGIÃO & $\begin{array}{r}\text { POPULAÇÃO } \\
\text { (milhões de ha- } \\
\text { bitantes) }\end{array}$ & $\begin{array}{r}\text { NÚMERO } \\
\text { TOTAL } \\
\text { ONG }\end{array}$ & $\begin{array}{r}\text { NÚMERO } \\
\text { EMPRESAS } \\
\text { ISO 14.000 }\end{array}$ & $\begin{array}{r}\text { INVESTIMENTO } \\
\text { (dólares per } \\
\text { cápita) }\end{array}$ & $\begin{array}{r}\text { ESTRANGEIRO } \\
\text { DIRETO } \\
\text { (milhões de dóla- } \\
\text { res) }\end{array}$ \\
\hline América do Norte & 319.925 .000 & 10.560 & 1517 & 33.341 & 292.463 \\
\hline América Central e Caribe & 178.512 .000 & 15.931 & 194 & 7.226 & 17.503 \\
\hline América do Sul & 355.695 .000 & 19.580 & 521 & 7.374 & 61.310 \\
\hline
\end{tabular}

(Fonte World Bank - Ano 2002)

Quadro 2: Indicadores demográficos, econômicos e de desenvolvimento sustentável de países americanos agrupados em três conjuntos segundo o número total de ONGs.

\begin{tabular}{|c|c|c|c|c|c|}
\hline $\begin{array}{l}\text { ONG } \\
\text { (número } \\
\text { total) }\end{array}$ & PAÍSES & $\begin{array}{r}\text { POPULAÇÃO } \\
\text { (milhões de ha- } \\
\text { bitantes) }\end{array}$ & $\begin{array}{r}\text { PIB } \\
\text { (total) }\end{array}$ & $\begin{array}{r}\text { INVESTIMENTOS } \\
\text { ESTRANGEIROS DI- } \\
\text { RETOS (milhões de dó- } \\
\text { lares) }\end{array}$ & $\begin{array}{r}\text { NÚMERO DE } \\
\text { EMPRESAS } \\
\text { ISO 14.000 }\end{array}$ \\
\hline$>4000$ & ESTADOS UNIDOS / CANADÁ & 320.2 & 11.266 & 292.463 & 1.517 \\
\hline $\begin{array}{l}<3200 \\
>1300\end{array}$ & $\begin{array}{l}\text { BRASIL / ARGENTINA / MÉ- } \\
\text { XICO / CHILE / COLÔMBIA / } \\
\text { VENEZUELA/ PERU / URU- } \\
\text { GUAI / COSTA RICA }\end{array}$ & 433.4 & 3452 & 72.180 & 697 \\
\hline $\begin{array}{l}<1200 \\
>350\end{array}$ & $\begin{array}{l}\text { EQUADOR / BOLÍVIA / GUA- } \\
\text { TEMALA / PANAMÁ / CUBA / } \\
\text { PARAGUAI / R. DOMINICANA } \\
\text { / JAMAICA / SALVADOR / } \\
\text { HONDURAS / NICARÁGUA / } \\
\text { TRINIDAD \& TOBAGO / HAITI } \\
\text { / BELIZE / GUIANA / SURI- } \\
\text { NAME }\end{array}$ & 94.6 & 383 & 6.217 & 9 \\
\hline
\end{tabular}

(Fonte World Bank - Ano 2002)

Por outro lado, o sucesso do discurso ético neoliberal propondo o voluntariado para a sociedade civil e a responsabilidade social para as empresas pode ser observado no crescimento das ONGs e das empresas com certificado ISO 14000 nos países com maior PIB e que captam maior volume de investimento estrangeiro para desenvolver sua economia segundo as regras do capitalismo mundial.

Para estabelecer a correlação entre o número total de ONGs e o contexto socioeconômico de cada país da região, no quadro 3 são mostrados dados correspondentes aos países do continente americano citados no relatório World Resources Report 2002-04 (WRI, 2004). Esse relatório do Programa das Nações Unidas para o Desenvolvimento (PNUD) foi elaborado em parceria com o Programa das Nações Unidas para o Meio Ambiente (PNUMA), o Banco Mundial e o Instituto de Recursos Mundiais.

Na quadro 3 aparecem os países americanos segundo o número total de ONGs em atividade no seu território e os resultados dos indicadores demográficos, econômicos, de desenvolvimento humano e de desenvolvimento sustentável. Os dados correspondentes aos indicadores IDH (Índice de Desenvolvimento Humano), IPH-1 (Índice de Pobreza Humana para Países em Desenvolvimento) e C-IDH - C-PIB (classificação do PIB per capita menos classificação do IDH) foram tirados do relatório Human Development Report 2004 - Cultural Liberty in Today's Diverse World do PNUD (UNDP, 2004). Uma análise qualitativa integral dos dados que aparecem no quadro 3 permite observar que:

- é grande a diferença entre esses indicadores nos países desenvolvidos da América do Norte (EUA e Canadá) e os indicadores de todos os outros países do continente americano; 
- os nove países com maior número total de ONGs são, ao mesmo tempo, os nove mais populosos e os de maior PIB total no continente. Mesmo assim, o resultado dos indicadores vinculados ao Desenvolvimento Humano não é homogêneo nesse grupo;

- os três países com menor número total de ONGs são os três países menos populosos do continente (menos de 1 milhão de habitantes) e, em função disso, são também os três com o menor PIB total. Esses resultados também não estão correlacionados com os indicadores de desenvolvimento humano;

- a correspondência entre o número de habitantes, o PIB e o número total de ONGs acaba na décima e na décima primeira posição dessa classificação, na qual dois países se colocam acima de outros países mais populosos. É o caso do Uruguai e da Costa Rica, com pequena população e, conseqüentemente, com um PIB total relativamente baixo. Esse fenômeno, que também se observa entre os nove primeiros países, mostra que países com boa performance nos indicadores de desenvolvimento humano (IDH, IPH-1 e C-IDH - C-PIB) abrigam maior número total de ONGs que outros mais populosos, mas, com características sociais diferentes. É o caso do Canadá em relação ao Brasil, da Argentina em relação ao México, do Chile em relação à Colômbia e da Venezuela em comparação com o Peru;

- os outros países da região que apresentam bons resultados de IDH, no entanto, não acompanham essa tendência, ou seja, têm população pequena (Panamá e Trinidad e Tobago) ou uma organização econômica centralizada no Estado, com uma sociedade civil organizada de modo diferente, como é o caso de Cuba;

- no extremo oposto, o país que apresenta a pior posição na classificação é o Haiti, que em termos de número de habitantes ocupa o décimo quinto lugar, com mais de 8 milhões de habitantes, e o último lugar em termos de desenvolvimento humano. Na classificação baseada no número total de ONGs ativas no seu território, somente superam os três países únicos com menos de 1 milhão de habitantes;

- número de usuários de Internet, considerado um indicador de acesso à informação pelo Banco Mundial e pelo PNUD, tem pouca relação com o número total de ONGs desses países;

- quanto aos indicadores de desenvolvimento sustentável, o resultado é desigual. Não se observa relação entre os municípios comprometidos com a Agenda 21 (um indicador muito pouco consistente) e os indicadores demográficos, econômicos ou de desenvolvimento humano. Quanto ao número de empresas que obtiveram a certificação ISO 14000, esse número é maior entre os 11 países com maior número total de ONGs. 
Quadro 3 - Indicadores demográficos, econômicos, sociais e de desenvolvimento sustentável para os países americanos, segundo o ranking do número total de ONGs

\begin{tabular}{|c|c|c|c|c|c|c|c|c|c|c|c|c|c|c|}
\hline $\begin{array}{r}\text { PAÍS } \\
\text { Classificação segundo o } \\
\text { Ranking do } \mathbf{N}^{\circ} \text { total de ONG }\end{array}$ & 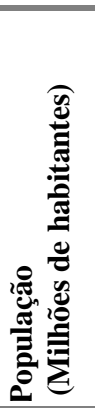 & 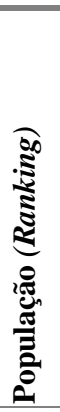 & 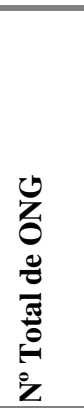 & 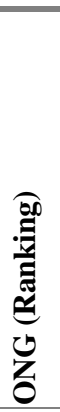 & 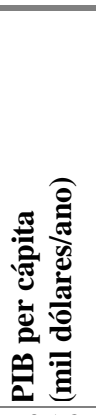 & 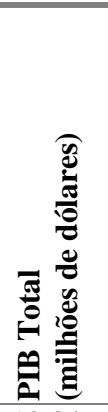 & 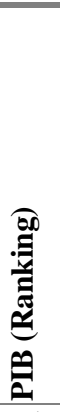 & 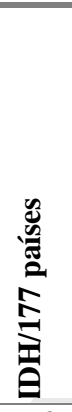 & 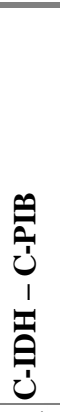 & 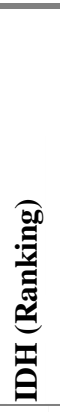 & 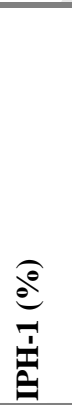 & 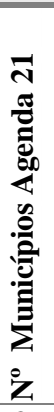 & 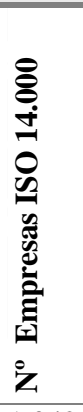 & 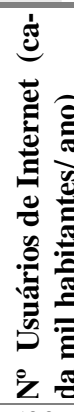 \\
\hline USA & 289 & 1 & 6348 & 1 & 35.8 & 10.346 & 1 & 8 & -4 & 2 & -- & 87 & 1.042 & 500 \\
\hline CANADÁ & 31,2 & 6 & 4150 & 2 & 29,5 & 920 & 3 & 4 & 5 & 1 & -- & 14 & 475 & 435 \\
\hline BRASIL & 175 & 2 & 3144 & 3 & 7.78 & 1361 & 2 & 72 & -9 & 13 & 11.8 & 36 & 330 & 46 \\
\hline ARGENTINA & 38 & 5 & 2812 & 4 & 10.9 & 414 & 5 & 34 & 14 & 3 & -- & 1 & 114 & 80 \\
\hline MÉXICO & 102 & 3 & 2754 & 5 & 8.97 & 915 & 4 & 53 & 5 & 8 & 9.1 & 2 & 159 & 35 \\
\hline CHILE & 15,6 & 9 & 2184 & 6 & 9.82 & 153 & 7 & 43 & 11 & 4 & 4.1 & 15 & 11 & 201 \\
\hline COLÔMBIA & 43,5 & 4 & 1956 & 7 & 6.37 & 277 & 6 & 73 & 4 & 14 & 8.1 & 6 & 21 & 27 \\
\hline VENEZUELA & 25,1 & 8 & 1908 & 8 & 5.38 & 135 & 8 & 68 & 21 & 12 & 8.5 & 3 & 7 & 53 \\
\hline PERU & 26,5 & 7 & 1744 & 9 & 5.01 & 133 & 9 & 85 & 7 & 16 & 13.2 & 17 & 13 & 115 \\
\hline URUGUAI & 3,4 & 21 & 1525 & 10 & 7.83 & 26.6 & 17 & 46 & 16 & 6 & 3.6 & -- & 22 & 119 \\
\hline COSTA RICA & 4,2 & 20 & 1462 & 11 & 8.84 & 37 & 14 & 45 & 14 & 5 & 4.4 & 4 & 20 & 93 \\
\hline EQUADOR & 13,1 & 10 & 1323 & 12 & 3.58 & 47 & 13 & 100 & 11 & 20 & 12.0 & 13 & 1 & 25 \\
\hline BOLÍVIA & 8,7 & 13 & 1267 & 13 & 2.46 & 21 & 18 & 114 & 6 & 23 & 14.1 & 1 & 1 & -- \\
\hline GUATEMALA & 12,0 & 11 & 1104 & 14 & 4.08 & 49 & 12 & 121 & $\begin{array}{r}- \\
15\end{array}$ & 26 & 22.5 & -- & 2 & 17 \\
\hline PANAMÁ & 2,9 & 22 & 1027 & 15 & 6.17 & 18 & 19 & 61 & 18 & 10 & 7.7 & -- & -- & -- \\
\hline CUBA & 11,3 & 12 & 1006 & 16 & 5.26 & 59 & 10 & 52 & 39 & 7 & 5.0 & 2 & -- & 11 \\
\hline PARAGUAI & 5,8 & 18 & 992 & 17 & 4.61 & 27 & 16 & 89 & 9 & 17 & 13.2 & -- & 1 & 11 \\
\hline R. DOMINICANA & 8,6 & 14 & 912 & 18 & 6.64 & 57 & 11 & 98 & $\begin{array}{r}- \\
27\end{array}$ & 18 & 13.7 & -- & 1 & 22 \\
\hline JAMAICA & 2,6 & 23 & 902 & 19 & 3.98 & 10 & 24 & 79 & 28 & 15 & 9.2 & 5 & -- & 38 \\
\hline EL SALVADOR & 6,5 & 17 & 858 & 20 & 4.89 & 32 & 15 & 103 & -9 & 21 & 17.0 & -- & -- & -- \\
\hline HONDURAS & 6,7 & 16 & 831 & 21 & 2.6 & 17 & 20 & 115 & 3 & 24 & 16.6 & 6 & 2 & -- \\
\hline NICARÁGUA & 5,3 & 19 & 815 & 22 & 2.47 & 13.1 & 22 & 118 & 1 & 25 & 18.3 & 5 & -- & -- \\
\hline TRINIDAD y TOBAGO & 1,3 & 24 & 812 & 23 & 9.43 & 12 & 23 & 54 & 1 & 9 & 7.7 & 1 & 1 & 92 \\
\hline HAITI & 8.4 & 15 & 621 & 24 & 1.61 & 13.5 & 21 & 153 & -9 & 27 & 41.1 & -- & -- & 4 \\
\hline BELIZE & 0.24 & 27 & 474 & 25 & 6.08 & 1.45 & 27 & 99 & $\begin{array}{r}- \\
19\end{array}$ & 19 & 16.7 & -- & -- & 78 \\
\hline GUIANA & 0.77 & 25 & 446 & 26 & 4.62 & 3.5 & 25 & 104 & -1 & 22 & 12.9 & 1 & -- & 124 \\
\hline SURINAME & 0.42 & 26 & 350 & 27 & 6.59 & 2.8 & 26 & 67 & 6 & 11 & -- & -- & -- & 35 \\
\hline
\end{tabular}

Fonte: WRI (2004) e UNDP (2004).

\section{As regras do jogo do neoliberalismo e as limitações das ONGs}

Para Marx, a sociedade civil é todo o conjunto das relações materiais entre os indivíduos num determinado grau de desenvolvimento das formas produtivas. Gramsci considera que a sociedade civil é o conteúdo ético do Estado (BOBBIO, 1994). Todavia, para o neoliberalismo, a sociedade civil se reduz ao terceiro setor. Um parágrafo do livro de Eduardo Szazi dispensa maiores explicações a respeito:

“... no campo social, as transformações no mercado e na sociedade brasileira nos últimos 30 anos conduziram a uma redistribuição dos papéis de cada ator social no alcance do bem comum, onde, 
progressivamente, a sociedade civil organizada assumiu novas responsabilidades pela proteção e defesa dos direitos, antes inseridas na órbita exclusiva do Estado (Primeiro Setor), posto que, até aquele momento, a empresa privada (Segundo Setor) entendia que sua função social era limitada ao pagamento de impostos e geração de empregos. O crescimento do número de organizações da sociedade civil verificado desde os anos $1970 \mathrm{fez}$ surgir um novo ator social, denominado Terceiro Setor, o conjunto de agentes privados com fins públicos, cujos programas visam atender direitos sociais básicos e combater a exclusão social e, mais recentemente, proteger o patrimônio ecológico brasileiro" (SZAZI, 2000, p.22).

O problema do discurso liberal não está no seu conteúdo ético convocando ao trabalho voluntário; pelo contrário, o trabalho social privado, bem conduzido, pode ajudar a minorar o sofrimento de muitas pessoas. Contudo, não podemos acreditar que esse é o caminho privilegiado para garantir direitos sociais, proporcionar inclusão social e proteger o patrimônio ecológico, como quer Szazi. A razão dessa desconfiança está, por um lado, no fato de que os direitos sociais são, por definição, direitos positivos cuja regulamentação tem de ser garantida pelo Estado. Por outro lado, decorre do fato de que a exclusão social e a degradação do meio ambiente são consequiências estruturais do modelo de produção e consumo neoliberal, assumido pelo capitalismo globalizado. Mesmo que se diga preocupado com a inclusão social e o desenvolvimento ambientalmente sustentável, o capitalismo continua tendo como objetivo o lucro imediato e crescente.

Nesse contexto, o campo de atuação da gestão ambiental se ampliou. Da abordagem de questões como a poluição local passou a tratar das ameaças e intervenções globais. Ao mesmo tempo, os desafios enfrentados pela sociedade não se limitam mais ao campo dos custos adicionais e dos ajustes técnicos relativamente simples; mas passou a abarcar igualmente as negociações, discussões, ameaças, conflitos, opções e incertezas.

É impossível continuar a pensar a gestão ambiental sem pensar na negociação com a sociedade civil. Contudo, o discurso ético neoliberal põe limites à identificação dos stakeholders interlocutores da mesma. Ao reduzir a sociedade civil ao terceiro setor, o neoliberalismo lhe tira o conteúdo político (ao separá-la do Estado) e o conteúdo econômico (ao separá-la dos meios de produção de riqueza). Uma vez despolitizada e excluída dos conflitos de classe, resta à (neo)sociedade civil apenas o trabalho voluntário, perdendo a vocação hegemônica para desenhar a realidade material, as relações sociais e a emancipação do homem.

Como explica Bobbio (1986), esse modo de fazer política através de movimentos sociais ou de opinião, na medida em que é reconhecido e tolerado pelo sistema e faz parte das regras do jogo, não pode ter como efeito a transformação do próprio sistema. No máximo, pode aspirar a algumas reformas superficiais.

Noam Chomsky, em entrevistas a David Barsamian publicadas no livro Segredos, mentiras e democracia, de 1999, afirma que a despolitização das organizações civis é uma estratégia das grandes corporações, que desde a década de 1980 contam com o apoio dos governos e das elites para concentrar o poder decisório nas mãos do poder financeiro. Para Chomsky, somente assim puderam se realizar as enormes transferências de recursos financeiros para subsidiar os mais ricos em detrimento das políticas sociais que caracterizaram as décadas anteriores. Segundo Chomsky, a democracia de Thomas Jefferson e John Dewey, e o liberalismo ilustrado de Adam Smith, exigem uma sociedade civil politizada que formule os destinos das políticas públicas; caso contrário, isso será feito pelos poderosos, e no lugar de democracia surgirá uma aristocracia. (CHOMSKY, 1999).

\section{Conclusões}

Deve ser diferenciado o status das ONGs que, como sociedade civil politizada, militam pelos direitos civis e políticos através do compromisso de cidadãos convocados por ideais de justiça e liberdade daquele terceiro setor despolitizado que, mascarado de trabalho voluntário, pretende cobrir parte da dívida social do Estado. O objetivo velado da estratégia global que promove o terceiro setor como o mais novo responsável pelo "social" é 
que o Estado permaneça mínimo na implementação de políticas compensatórias, porém, forte para impor o padrão de distribuição de riqueza que nos últimos anos vem incrementando o hiato que separa os mais ricos dos mais pobres. Nesse contexto, as últimas décadas mostram que as grandes corporações vêm concentrando poder político e financeiro no mesmo ritmo em que o planeta se degrada e multidões são condenadas à exclusão social. A grande limitação das ONGs na América Latina, como espaço politizado capaz de contribuir para a transformação da realidade, está em lutar contra a exclusão social e a degradação ambiental dentro das regras do jogo impostas em nível mundial pelo capitalismo neoliberal. A principal razão para os movimentos sociais se sujeitarem às regras de jogo do sistema - o que revela a debilidade das propostas alternativas no sentido de alterar a correlação de forças dominante - é que a única alternativa à luta regulada é a vitória do mais forte.

Finalmente, cabe enfatizar que deve ser construído um Estado social de direito, com uma sociedade civil emancipada, autônoma (e, portanto, hegemônica) que participe ativamente na organização social do trabalho, da produção e na distribuição de riquezas, realçando o pluralismo e abolindo as exclusões. Isso requer resgatar valores éticos, trabalhar de forma participativa pela inclusão e pela justiça social através de organizações populares politizadas, solidárias, engajadas e sem medo de transformar a realidade, sabendo que, apesar das crises e das incertezas, a mudança não só é possível, mas que, inexoravelmente, um dia virá. Gramsci, que compreendia muito bem as épocas de crises e incertezas, disse: "a crise consiste exatamente no fato de que o velho morre e o novo não consegue nascer" (GRAMSCI, 1975, p.311). Por enquanto, vale a pena continuar denunciando o projeto político-econômico por trás do discurso ético do terceiro setor. Tal como foi expresso no Fórum Social Mundial de 2001, em Porto Alegre, essa denúncia é crucial, pois "os efeitos da nova vulgata são tão poderosos e perniciosos que ela é veiculada não apenas pelos partidários do neoliberalismo, mas por produtores culturais e militantes de esquerda que, em sua maioria, ainda se consideram progressistas" (BORDIEU e WACQUANT, 2001, p.156). 


\section{Referências bibliográficas}

BOBBIO, N. O futuro da democracia. [S.I.]: Paz e Terra, 1986.

A era dos direitos. Rio de Janeiro: Campus, 1992.

O conceito de sociedade civil. Rio de Janeiro: Edições Graal, 1994.

BORDIEU, P.; WACQUANT, L. A nova Bíblia do Tio Sam. In: CATTANI, A. (Org.). Fórum Social Mundial: a construção de um mundo melhor. Petrópolis: Vozes, 2001. p.156-161

BRUGGER, E.; LIZANO, E. (Ed.). Eco eficiência: la visión empresarial para el desarrollo sostenible en América Latina. Bogotá: Oveja Negra, 2000.

CGG - Comissão sobre Governança Global. Nosso futuro comum. Rio de Janeiro: FGV, 1996.

CHOMSKY, N. Segredos, mentiras e democracia: entrevistas a David Barsamian. Brasília, DF: UnB Editora, 1999.

DOM INGUES, J. M. Cidadania, direitos e modernidade. In: SOUZA, J. Democracia hoje: novos desafios para a teoria democrática contemporânea. Brasília: UnB Editora, 2001.

ENGELHARDT, H. Fundamentos da bioética. São Paulo: Loyola, 1998.

GALEANO, E. Ser como eles. Rio de Janeiro: Revan, 1994.

. Úselo y tírelo: el mundo visto desde una ecología latinoamericana. Buenos Aires: Booket, 2004.

GCS - Global Civil Society. Yearbook 2003. Disponível em: <http://www.lse.ac.uk/Depts/global/Yearbook/PDF/PDF2003/, 2003>. Acessado em: 12 out. 2004.

GRAMSCl, A. Quaderni del carcere, Einaudi, Torino, n.3, 1975.

ISO - International Organization for Standardization. Disponível em: <http://www.iso.ch/iso/en/prodsservices/otherpubs/iso14000/index.html, 2002>. Acessado em: 12 out. 2004.

LOCKE, J. Segundo tratado sobre o governo civil. Petrópolis: Vozes, 2001.

M CM ICHAEL, A. J. Planetary overload: global environmental change and the health of the human species. Cambridge: Cambridge University Press, 1993.

NOZICK, R. Anarchy, State and utopia. New York: Basic Books, 1974.

ONU - Organização das Nações Unidas. Disponível em:

<http://www.un.org/esa/sustdev/documents/WSSD_POI_PD/Spanish/WSSDsp_PD.htm. 2002>. Acessado em: 12 out. $2004 a$.

. Disponível em: <http://www.un.org/esa/population/unpop.htm, 2002>. Acessado em: 12 out. 2004b.

OPS - Organización Panamericana de la Salud. Nuestro planeta, nuestra salud: informe de la Comisión de Salud y Medio Ambiente de la OMS. Washington: OPS, 1993.

SANTOS, Boaventura de Sousa, 1987, 0 Estado, a Sociedade e as Políticas Sociais: 0 caso das políticas de saúde. In: Revista crítica de Ciências Sociais. №23 (13-74), Setembro 1987.

SCHM IDHEINY, S. Mudando o rumo: uma perspectiva empresarial global sobre desenvolvimento e meio ambiente. Rio de Janeiro: Editora FGV, 1992.

SZAZI, E. Terceiro setor: regulação no Brasil. São Paulo: Petrópolis, 2000.

UAI - Union of International Associations, 2002. Disponível em: <http://www.uia.org/>. Acessado em: 12 out. 2004.

UNDP - United Nations Environmental Program. Human development report 2004 - cultural liberty in today's diverse world. Disponível em: <http://hdr.undp.org/reports/global/2004/>. Acessado em: 12 out. 2004.

VALLE, C. E. Qualidade ambiental: ISO 14000. São Paulo: Editora Senac, 2002.

VITA, A. A J ustiça igualitária e seus críticos. São Paulo: Unesp, 2000.

WALZER, M., 2001 Las esferas de la justicia. Una defensa del pluralismo y la igualdad, Fondo de Cultura Económica, México.

WB - World Bank. World Bank, 2002. Disponível em: <http://www.worldbank.org/data>. Acessado em: 12 out. 2004a.

World Bank and civil society, 2004. Disponível em:

<'ttp://web.worldbank.org/WBSITE/EXTERNAL/TOPICS/CSO/0,pagePK:220469 theSitePK:228717,00.html>. Acessado em: 12 out. $2004 \mathrm{~b}$. 
WRI - World Resources Institute. World Resources report 2002-04 - decisions for the Earth. Balance, voice, and power. United Nations Development Program (UNDP), United Nations Environmental Program (Unep), World Bank \& World Resources Institute (WRI). Disponível em: <http://earthtrends.wri.org , 2002>. Acessado em: 12 out. 2004. 